\title{
Phosphine-Free Suzuki-Miyaura Cross-Coupling in Aqueous Media Enables Access to 2-C-Aryl-Glycosides
}

\begin{tabular}{|r|l|}
\hline Journal: & Organic Letters \\
\hline Manuscript ID: & Ol-2012-003139.R1 \\
\hline Manuscript Type: & Communication \\
\hline Author: & O1-Mar-2012 \\
\hline Complete List of Authors: & $\begin{array}{l}\text { Cobo, Isidro; University of Oxford, Department of Chemistry } \\
\text { Matheu, M.; University Rovira i Virgili, Química Analítica i Química } \\
\text { Orgànica } \\
\text { Castillon, Sergio; URV, QAQO } \\
\text { Boutureira, Omar; URV, QAQO; University of Oxford, Department of } \\
\text { Chemistry } \\
\text { Davis, Benjamin; University of Oxford, Department of Chemistry }\end{array}$ \\
\hline
\end{tabular}

\section{SCHOLARONE ${ }^{m}$ Manuscripts}




\title{
Phosphine-Free Suzuki-Miyaura Cross-Coupling in Aqueous Media Enables Access to 2-C- Aryl-Glycosides
}

\author{
Isidro Cobo, ${ }^{\dagger, \ddagger}$ M. Isabel Matheu, ${ }^{\ddagger}$ Sergio Castillón, ${ }^{\ddagger}$ Omar

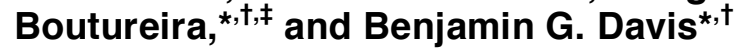

Department of Chemistry, University of Oxford, Chemistry Research Laboratory, 12 Mansfield Road, Oxford OXI 3TA, UK, and Departament de Química Analítica i Química Orgànica, Universitat Rovira i Virgili, C/ Marcel-lí Domingo s/n, 43007 Tarragona, Spain omar.boutureira@urv.cat; ben.davis@chem.ox.ac.uk Received Date (will be automatically inserted after manuscript is accepted)

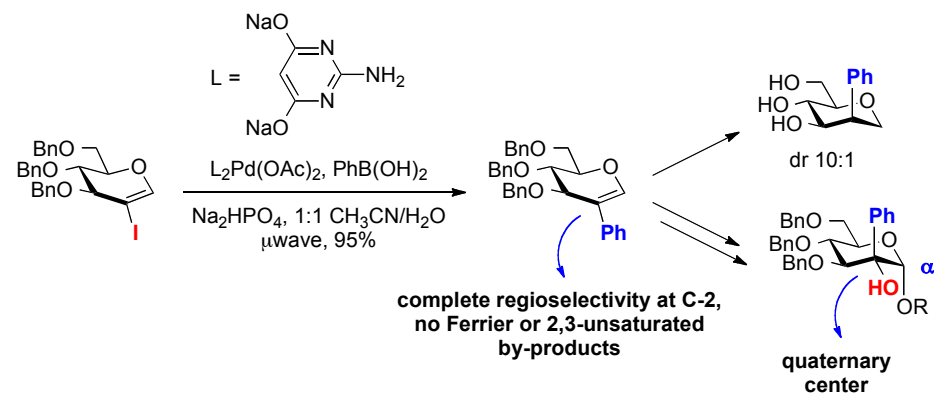

A general strategy for the synthesis of 2-aryl-glycals and their elaboration to 2-C-aryl-a-glycosides and 1,5-anhydro2-C-aryl-2-deoxy alditols is described. The use of reliable, efficient phosphine-free Suzuki-Miyaura cross-coupling of 2-iodoglycals in aqueous media as a key step proceeds with complete regioselectivity at C-2 and enables access to 2-aryl-glycals with different configurations in excellent yields.

$C$-Aryl-glycosides are members of the $C$-glycosides ${ }^{1}$ family of carbohydrate mimetics and their synthesis has attracted considerable interest due to the presence of such motifs in several naturally occurring bioactive products. ${ }^{2}$

'University of Oxford.

"Universitat Rovira i Virgili.

(1) (a) Štambaský, J.; Hocek, M.; Kočovský, P. Chem. Rev. 2009, 109, 6729. (b) The Chemistry of C-Glycosides, Levy, D. E., Tang, C.; Elsevier: Oxford, 1995. (c) Yuan, X.; Linhardt, R. J. Curr. Top. Med. Chem. 2005, 5, 1393. (d) Du, Y.; Linhardt, R. J.; Vlahov, I. R. Tetrahedron 1998, 54, 9913. (e) Beau, J.-M.; Gallagher, T. Top. Curr. Chem. 1997, 187, 1. (f) Sinaÿ, P. Pure Appl. Chem. 1997, 69, 459. (g) Postema, M. H. D. Tetrahedron 1992, 48, 8545.

(2) (a) Bililign, T.; Griffith, B. R.; Thorson, J. S. Nat. Prod. Rep. 2005, 22, 742. (b) Hultin, P. G. Curr. Top. Med. Chem. 2005, 5, 1299 (c) Zou, W. Curr. Top. Med. Chem. 2005, 5, 1363. (d) Moose, E. V.; Ben, R. N. Curr. Top. Med. Chem. 2005, 5, 1351. (e) Compain, P.; Martin, O. R. Bioorg. Med. Chem. 2001, 9, 3077. (f) Nicotra, F. Top. Curr. Chem. 1997, 187, 55.
Many methods have been developed for the synthesis of 1-C-arylglycosides where a carbon atom substitutes the anomeric glycosidic oxygen. ${ }^{3}$ The most common method for 1-C-arylglycosides synthesis involves the use of transition metal-catalyzed reactions, in particular, the addition of organometallic species to the $\mathrm{sp}^{2}$-hybridized anomeric center of glycals. ${ }^{4}$ Regioselectivity may be

(3) (a) Subrahmanyam, A. V.; Palanichamy, K.; Kaliappan, K. P. Chem.-Eur. J. 2010, 16, 8545 and references therein. (b) Lee, D. Y. W.; He, M. Curr. Top. Med. Chem. 2005, 5, 1333. (c) Martin, S. F. Pure Appl. Chem. 2003, 75, 63 .

(4) (a) Xiang, S.; Cai, S.; Zeng, J.; Liu, X.-W. Org. Lett. 2011, 13, 4608. (b) Bai, Y.; Leow, M.; Zeng, J.; Liu, X.-W. Org. Lett. 2011, 13 5648. (c) Xiong, D.-C.; Zhang, L.-H.; Ye, X.-S. Org. Lett. 2009, 11, 1709. (d) Li, H.-H.; Ye, X.-S. Org. Biomol. Chem. 2009, 7, 3855. (e) de la Figuera, N.; Forns, P.; Fernàndez, J.-C.; Fiol, S.; Fernández-Forner, 
efficiently controlled using a directing halogen atom at the anomeric position ${ }^{5}$ (e.g. 1-haloglycals). However, and when this regiocontrol element is missing, reactions often lead to the formation of Ferrier and other 2,3-unsaturated products due to $\beta$-elimination processes ${ }^{4-7}$ Although the high demand for functionalized 1-C-arylglycosides has stimulated extensive studies on metal-catalyzed C-C bond-forming reactions, ${ }^{8}$ the development of more efficient methods that involve arylation at other positions is highly desirable. $C$-Functionalizations at other positions of the sugar ring leading to $C$-branched sugars are by far less explored because they usually require many steps, ${ }^{9}$ the use of strongly basic organolithium and Grignard reagents, ${ }^{10}$ or the use of toxic reagents such as tin or mercury. ${ }^{11}$ Particularly, the synthesis of 2-C-arylmodified-carbohydrates ${ }^{12}$ is rare, even though they are of potential interest for the development of new biologically active carbohydrate mimetics.

We envisaged a general strategy for accessing 2-arylglycals (Scheme 1) as key intermediates for synthesizing $2-C$-arylglycosides. We anticipated that this could be achieved through the use of 2-haloglycals as privileged starting materials for this transformation featuring a regiocontrol element at the desired C-2 position. ${ }^{13-15}$ Herein we report a general and efficient method for the synthesis of 2-arylglycals 9 with different configurations under relatively mild conditions by an aqueous, phosphine-free Suzuki-Miyaura cross-coupling of 2-iodoglycals 5-8 with aryl boronic acids in the presence of an inexpensive Pd complex ${ }^{16}$ (Scheme 1).

D.; Albericio, F. Tetrahedron Lett. 2005, 46, 7271. (f) Ramnauth, J.; Poulin, O.; Rakhit, S.; Maddaford, S. P. Org. Lett. 2001, 3, 2013.

(5) (a) Koester, D. C.; Liebeling, M.; Neufeld, R.; Werz, D. B. Org. Lett. 2010, 12, 3934. (b) Potuzak, J. S.; Tan, D. S. Tetrahedron Lett 2004, 45, 1797. (c) Somsák, L. Chem. Rev. 2001, 101, 81. (d) Jeanneret, V.; Meerpoel, L.; Vogel, P. Tetrahedron Lett. 1997, 38, 543.

(6) Daves, G. D., Jr. Acc. Chem. Res. 1990, 23, 201.

(7) Bai, Y.; Zeng, J.; Cai, S.; Liu, X.-W. Org. Lett. 2011, 13, 4394.

(8) Gong, H.; Gagné, M. R. J. Am. Chem. Soc. 2008, 130, 12177.

(9) (a) Koester, D. C.; Holkenbrink, A.; Werz, D. B. Synthesis 2010, 3217. (b) Yin, J.; Linker, T. Org. Biomol. Chem. 2009, 7, 4829. (c) Sridhar, P. R.; Kumar, P. V.; Seshadri, K.; Satyavathi, R. Chem.-Eur. J. 2009, 15, 7526. (d) Elamparuthi, E.; Kim, B. G.; Yin, J.; Maurer, M.; Linker, T. Tetrahedron 2008, 64, 11925. (e) Bouisset, T.; Gosselin, G.; Griffe, L.; Meillon, J.-C.; Storer, R. Tetrahedron 2008, 64, 6657. (f) Xavier, N. M.; Rauter, A. P. Carbohydr. Res. 2008, 343, 1523.

(10) Cleator, E.; McCusker, C. F.; Steltzer, F.; Ley, S. V. Tetrahedron Lett. 2004, 45, 3077.

(11) Giese, B.; González-Gómez, J. A.; Witzel, T. Angew. Chem. Int . Ed. Engl. 1984, 23, 69.

(12) (a) Robinson, T. V.; Pedersen, D. S.; Taylor, D. K.; Tiekink, E. R. T. J. Org. Chem. 2009,74,5093. (b) Maurya, S. K.; Hotha, S. Tetrahedron Lett. 2006, 47, 3307. (c) Willson, M.; Perie, J. Spectrochim. Acta Part A 1999, 55, 911. (d) Sugimura, H.; Osumi, K.; Koyama, T. Chem. Lett. 1991, 20,1379. (e) Augé, C.; Gautheron, C.; David, S.; Malleron, A.; Cavayé, B.; Bouxom, B. Tetrahedron, 1990, 46, 201. (f) Lee, J.B.; Scalon, B. J. Chem. Soc. D, Chem. Comun. 1969, 17, 955.

(13) (a) Hayashi, M.; Tsukada, K.; Kawabata, H.; Lamberth, C. Tetrahedron, 1999, 55, 12287. (b) Hayashi, M.; Amano, K.; Tsukada, K.; Lamberth, C. J. Chem. Soc., Perkin Trans. 1, 1999, 239. (c) Lamberth, C.; Bednarski, M. Carbohydr. Lett. 1995, 1, 369.

(14) Chemler, S. R.; Iserloh, U.; Danishefsky, S. J. Org. Lett. 2001, 3, 2949.

(15) (a) Leibeling, M.; Milde, B.; Kratzert, D.; Stalke, D.; Werz, D B. Chem-Eur. J. 2011, 17, 9888. (b) Leibeling, M.; Koester, D. C.; Pawliczek, M.; Schild, S. C.; Werz, D. B. Nat. Chem. Biol. 2010, 6, 199 (c) Leibeling, M.; Koester, D. C.; Pawliczek, M.; Kratzert, D; Dittrich, B.; Werz, D.B. Bioorg. Med. Chem. 2010, 18, 3656.

(16) (a) Spicer, C. D.; Davis, B. G. Chem. Commun. 2011, 47, 1698 (b) Chalker, J. M.; Wood, C. S. C.; Davis, B. G. J. Am. Chem. Soc 2009, $131,16346$.
Scheme 1. General strategy towards the preparation of 2-arylglycals 9
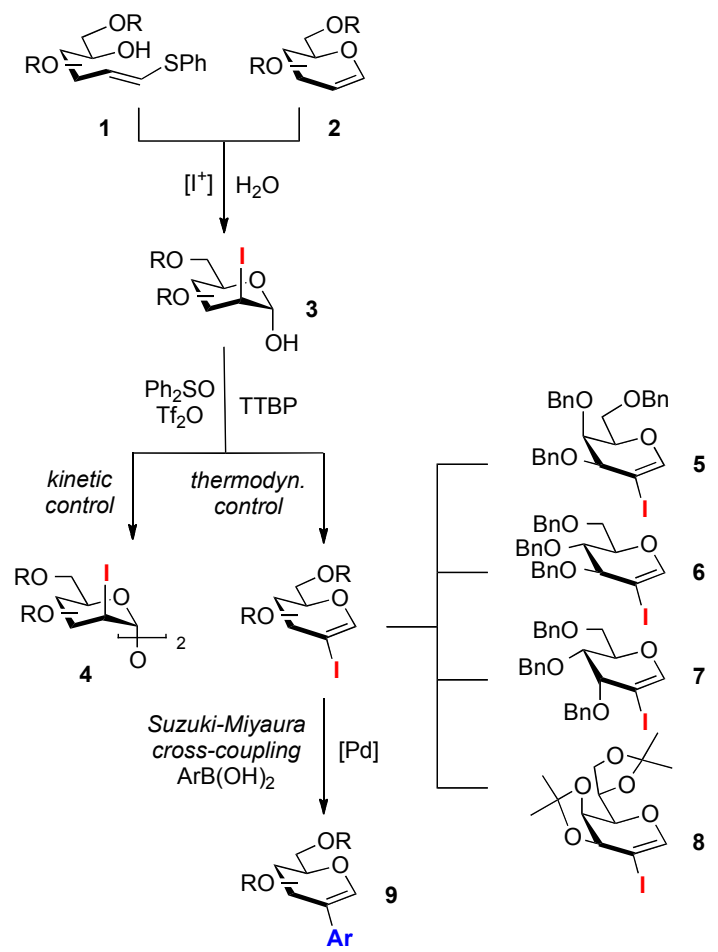

Although iodo-derivates are preferable over chlorine or bromine for these reactions ${ }^{17}$ they are less used, probably due to the lack of a general method for their preparation. ${ }^{18}$ Thus, starting 2-iodoglycals 5-8 were prepared by treating alkenyl sulfanyl derivatives $\mathbf{1}$ or commercially available glycals $\mathbf{2}$ with iodonium reagents in aqueous media to provide the corresponding 2-deoxy-2iodopyranoses $\mathbf{3}$ which were then eliminated with $\mathrm{Ph}_{2} \mathrm{SO} / \mathrm{Tf}_{2} \mathrm{O}$ and TTBP. Importantly, the optimization of original reaction conditions by driving the reaction under thermodynamic control allowed the selective preparation of otherwise elusive 2-iodoglycals 5 and $\mathbf{6}$ (see SI for details). Under kinetic control, 2-deoxy-2-iodo-trehaloses 4 were principally obtained. ${ }^{18,19}$

The feasibility of the Suzuki-Miyaura cross-coupling reaction was initially examined by using our recently developed $\mathrm{Pd}$ catalyst $^{16}$ (Table 1). Treatment of 2-iodogalactal 5 and phenylboronic acid 10a with $2 \mathrm{~mol} \%$ catalyst and $\mathrm{Na}_{2} \mathrm{HPO}_{4}$ in $1: 3 \mathrm{CH}_{3} \mathrm{CN} / \mathrm{H}_{2} \mathrm{O}$ afforded 2-phenylgalactal 11a in $82 \%$ yield with complete selectivity at C-2 after $300 \mathrm{~min}$ at $100{ }^{\circ} \mathrm{C}$ (entry 1). Attempts to decrease the catalyst loading proved ineffective (entry 2). Changing the solvent ratio from 1:3 to $1: 1 \mathrm{CH}_{3} \mathrm{CN} / \mathrm{H}_{2} \mathrm{O}$ to increase the solubility of $\mathbf{5}$, improved the yield of 11a to $90 \%$ after only $30 \mathrm{~min}$ at $100{ }^{\circ} \mathrm{C}$ (entry 3 ). Next, the effect of reaction temperature

(17) (a) Gómez, A. M.; Pedregosa, A.; Valverde, S.; López, J. C. Tetrahedron Lett. 2003, 44, 6111. (b) Gómez, A. M.; Danelón, G. O.; Pedregosa, A.; Valverde, S.; López, J. C. Chem. Commun. 2002, 2024.

(18) Rodríguez, M. A.; Boutureira, O.; Matheu, M. I.; Díaz, Y.; Castillón, S.; Seeberger, P. H. J. Org. Chem. 2007, 72, 8998.

(19) Backus, K. M.; Boshoff, H. I.; Barry, C. S.; Boutureira, O.; Patel, M. K.; D'Hooge, F.; Lee, S. S.; Via, L. E.; Tahlan, K.; Barry, C E.; Davis, B. G. Nat. Chem. Biol. 2011, 7, 228. 
was evaluated (entries 4-6), being $125{ }^{\circ} \mathrm{C}$ optimal. The best yield for 11a (95\%) was finally obtained with $2 \mathrm{~mol} \%$ catalyst in $1: 1 \mathrm{CH}_{3} \mathrm{CN} / \mathrm{H}_{2} \mathrm{O}$ at $125^{\circ} \mathrm{C}$ for only 5 min (entry 6). Globally, the use of this cheap and environmentally friendly catalyst provides several advantages; carrying out the reaction under aqueous conditions is key since the use of nonpolar solvents accelerates competing elimination reactions ${ }^{20}$ and also avoiding the use of degassed solvents combined with expensive, easily oxidized phosphines that are particularly detrimental for the success of this reaction. For example, we observed $40 \%$ hydrodehalogenation of 2-iodogalactal 5 when reacted with $\mathrm{PBu}_{3}$ (see SI for details).

Table 1. Optimization of reaction conditions for the Suzuki-Miyaura cross-coupling of 2-iodogalactal $\mathbf{5}$ with phenylboronic acid 10a ${ }^{\mathrm{a}}$

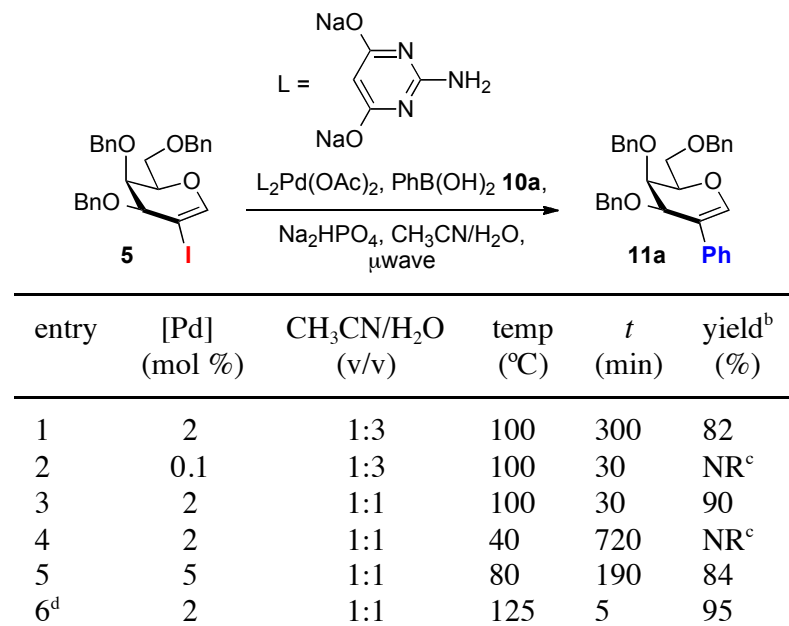

a Reactions were performed in a sealed vessel under single-mode microwave irradiation $(65$ W) with 2-I-galactal 5 (1 equiv), $\mathrm{PhB}(\mathrm{OH})_{2}$ 10a (1.5 equiv), $\mathrm{L}_{2} \mathrm{Pd}(\mathrm{OAc})_{2}$ (up to $5 \mathrm{~mol} \%$ ), and $\mathrm{Na}_{2} \mathrm{HPO}_{4}$ (5 equiv) in solvent $(0.02 \mathrm{M})$ unless otherwise indicated. ${ }^{\mathrm{b}}$ Isolated yield. ${ }^{c} \mathrm{NR}=$ no reaction $(>98 \%$ starting material was recovered). ${ }^{\mathrm{d}}$ Microwave power $(300 \mathrm{~W})$.

Encouraged by these results, a variety of arylboronic acids $\mathbf{1 0 b}-\mathbf{h}$ containing representative groups with potential in different imaging modalities ${ }^{21}$ (e.g. PET, MRI, and fluorescence) were examined to expand the scope of the Suzuki-Miyaura cross-coupling of 2-iodogalactal 5 (Table 2). Phenylboronic acids with electron-withdrawing groups (entries 1, 3, and 7) or electron-donating groups (entry 2) both afforded excellent results. Similarly, the use of sterically hindered boronic acids (entries 4 and 6), or heterocyclic derivatives (entry 5) also afforded excellent results although longer reaction times were required. Next, 2-iodoglycals 6-8 were reacted with phenylboronic acid 10a under the optimized reaction conditions (Table 1, entry 6) and 2-phenylglycals 12-14 were efficiently obtained in excellent yields (up to

(20) Gong, H.; Sinisi, R.; Gagné, M. R. J. Am. Chem. Soc. 2007, 129 , 1908.

(21) Spicer, C. D.; Triemer, T.; Davis, B. G. J. Am. Chem. Soc. 2012, 134,800 .
95\%) confirming that different configurations are compatible with this procedure (Table 3).

Table 2. Scope of Suzuki-Miyaura cross-coupling of 2-iodogalactal 5 with arylboronic acids $\mathbf{1 0 b}-\mathbf{h}^{\mathrm{a}}$

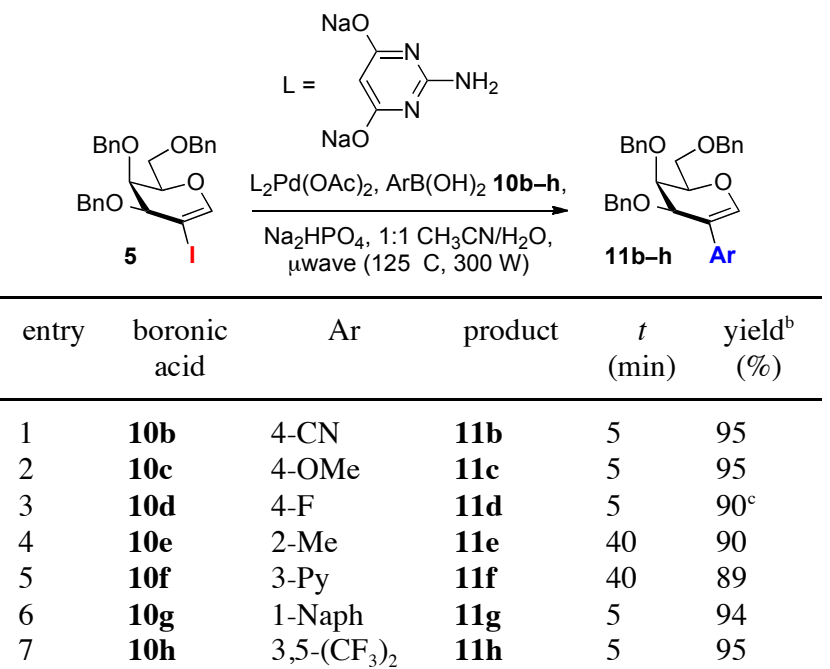

${ }^{\text {a }}$ Conditions: a mixture of 2-I-galactal 5 (1 equiv), $\operatorname{ArB}(\mathrm{OH})_{2}$ 10b-h (1.5 equiv), $\mathrm{L}_{2} \mathrm{Pd}(\mathrm{OAc})_{2}(2 \mathrm{~mol} \%)$, and $\mathrm{Na}_{2} \mathrm{HPO}_{4}$ (5 equiv) in $1: 1 \quad \mathrm{CH}_{3} \mathrm{CN} / \mathrm{H}_{2} \mathrm{O}(0.02 \mathrm{M})$ was microwave irradiated $\left(125{ }^{\circ} \mathrm{C}, 300 \mathrm{~W}\right)$ unless otherwise indicated. ${ }^{\mathrm{b}}$ Isolated yield. ${ }^{\mathrm{c}}$ Traces of 3,4,6-tri- $O$-benzyl-D-galactal were also detected (see Supporting Information for a mechanistic investigation).

Table 3. Scope of Suzuki-Miyaura cross-coupling of 2-iodoglycals 6-8 with phenylboronic acid ${ }^{\mathrm{a}}$

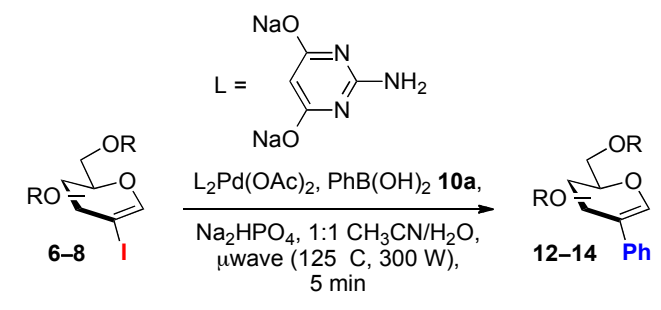

\begin{tabular}{|c|c|c|c|}
\hline entry & 2-I-glycal & product & yield $^{\mathrm{b}}(\%)$ \\
\hline 1 & $\underset{6}{\mathrm{BnO}}$ & $\begin{array}{c}\mathrm{BnO} \\
\mathrm{BnO} \\
\mathrm{BnO}\end{array}$ & $95^{\mathrm{c}}$ \\
\hline 2 & $\begin{array}{ll}\mathrm{BnO} \\
\mathrm{BnO}\end{array}$ & $\begin{array}{l}\mathrm{BnO} \\
13 \mathrm{BnO}\end{array}$ & 95 \\
\hline 3 & & & 96 \\
\hline
\end{tabular}

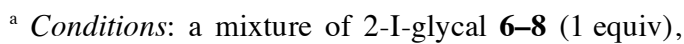
$\mathrm{PhB}(\mathrm{OH})_{2}$ 10a (1.5 equiv), $\mathrm{L}_{2} \mathrm{Pd}(\mathrm{OAc})_{2}(2 \mathrm{~mol} \%)$, and $\mathrm{Na}_{2} \mathrm{HPO}_{4}$ (5 equiv) in $1: 1 \mathrm{CH}_{3} \mathrm{CN} / \mathrm{H}_{2} \mathrm{O}(0.02 \mathrm{M})$ was microwave irradiated $\left(125^{\circ} \mathrm{C}, 300 \mathrm{~W}\right)$ for $5 \mathrm{~min}$ unless otherwise indicated. ${ }^{\mathrm{b}}$ Isolated yield. ${ }^{\mathrm{c}}$ Traces of 3,4,6-tri- $O$-benzyl-D-glucal were also detected (see Supporting Information for full details). 
Having demonstrated the success of the SuzukiMiyaura cross-coupling reaction with 2-iodoglycals, the potential of resulting 2-arylglycals as intermediates for the preparation of 2 - $C$-arylglycoconjugates was investigated. Thus, 2-phenylglucal $\mathbf{1 2}$ was efficiently hydrogenated with $\mathrm{Pd} / \mathrm{C}$ in methanol to afford 1,5anhydro-2-C-aryl-2-deoxy alditols $\mathbf{1 5}$ and $\mathbf{1 6}$ in 95\% yield and $d r \quad 10: 1$ as indicated by the analysis of diagnostic coupling constants and key NOE signals in $\mathbf{1 5}$ and $\mathbf{1 6}$ both present in their ${ }^{4} \mathrm{C}_{1}$ conformation (Scheme 2).

Scheme 2. Synthesis and conformational analysis of 1,5anhydro-2-C-aryl-2-deoxy alditols $\mathbf{1 5}$ and $\mathbf{1 6}$

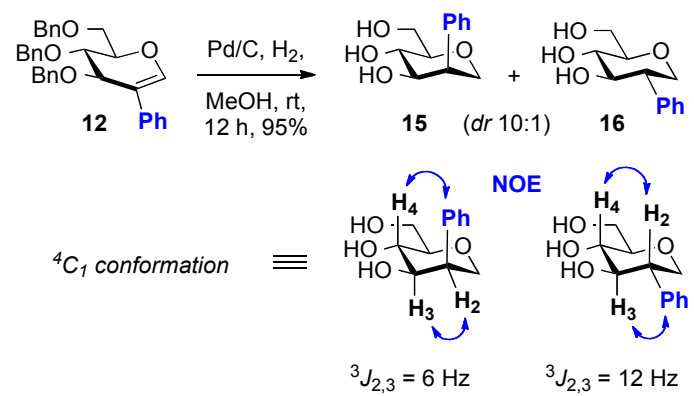

The preparation of challenging quaternary 2-C-aryl moieties was next studied using our two-step approach, which involves the epoxidation of starting 2-arylglycals followed by ring-opening of resulting $2-C$-aryl branched 1,2-anhydropyranosides. ${ }^{22}$ Thus, treatment of 2phenylglucal 12 with Oxone $^{\circledR}$ and acetone afforded epoxide 17 in quantitative yield ${ }^{23,24}$ (Scheme 3). Next, 2$C$-phenyloxirane 17 was subjected to an acid-promoted glycosylation with $\mathrm{EtOH}$ or $\mathrm{BnOH}$. Under such conditions, 2- $C$-phenylglycosides 18 and 19 were obtained in good yields (85-90\%) with exclusive $\alpha$-selectivity (Scheme 3). The stereochemistry of compounds 18 and 19 was initially deduced by analysis of diagnostic ${ }^{3} J_{3,4}=9.5 \mathrm{~Hz}$ coupling constants that account for a ${ }^{4} \mathrm{C}_{1}$ conformation. Moreover, the anomeric ${ }^{1} J_{\mathrm{C} 1-\mathrm{H} 1}=$ $174.8 \mathrm{~Hz}$ coupling constant is indicative of an $\alpha$-configuration. ${ }^{25}$ Finally, selective NOE irradiation of the aromatic $\mathrm{Ph}$ protons at $\mathrm{C}-2$ caused an enhancement of signals corresponding to $\mathrm{H}-1$ and $\mathrm{H}-4$, which confirmed the axial disposition of the $\mathrm{Ph}$ group at $\mathrm{C}-2$ in both $\mathbf{1 8}$ and 19.

In conclusion, we have developed a general catalytic strategy for the efficient synthesis of 2-arylglycals by phosphine-free Suzuki-Miyaura cross-coupling of 2-iodoglycals in aqueous media using an inexpensive Pd catalyst. To the best of our knowledge this transformation represents the first transition metal catalyzed $2-C$ -

(22) Danishefsky, S. J.; Bilodeau, M. T. Angew. Chem. Int. Ed. Engl. 1996, 35,1380

(23) Initial attempts using Gin's epoxidation conditions were unsuccessful, see: (a) Honda, E.; Gin, D. Y. J. Am. Chem. Soc. 2002 124, 7343 and references therein. (b) Kim, J.-Y.; Di Bussolo, V.; Gin. D. Y. Org. Lett. 2001, 3, 303 .

(24) Cheshev, P.; Marra, A.; Dondoni, A. Carbohydr. Res. 2006, 341, 2714.

(25) Tvaroska, I.; Taravel, F. R. Adv. Carbohydr. Chem. Biochem. 1995, 51,15 . arylation of 2-haloglycals. The simplicity and relative mildness of this method allows the regioselective preparation of various 2-arylglycals with different configurations in excellent yields with no Ferrier or 2,3-unsaturated by-products detected. Notably, the 2-iodoglycal substrates proved unstable in the presence of phosphines, necessitating systems that avoid their use. The elaboration of the 2-C-arylglycal moiety gives access to both 1,5-anhydro-2-C-aryl-2-deoxy alditols and challenging quaternary $2-C$-aryl- $\alpha$-glycosides which will broaden the plethora of 2-C-aryl branched glycosides at positions different than $\mathrm{C}-1$. Further application of this methodology to the synthesis of more complex 2-C-aryl branched glycosides is currently under investigation.

Scheme 3. Synthesis and conformational analysis of branched 2-C-phenylglycosides 18 and 19

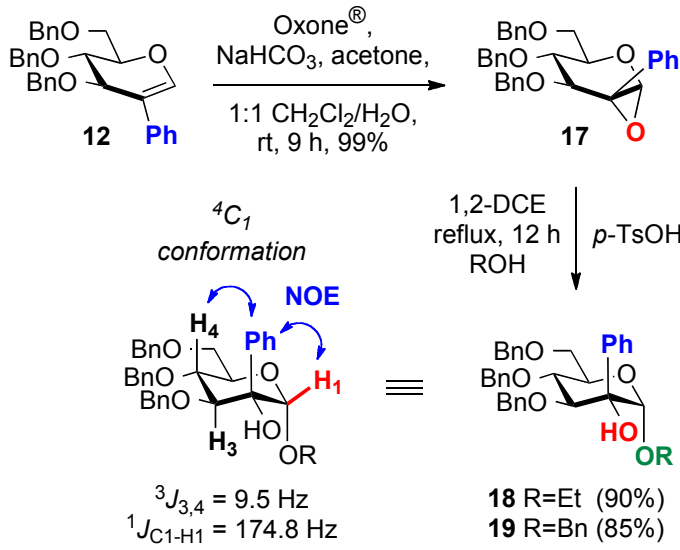

Acknowledgments We thank the European Commission (Marie Curie Intra European Fellowship, O.B.), DGI (CTQ2008-01569-BQU), and Ministerio de Ciencia y Tecnología, Spain (CSD2006-0003, Consolider Ingenio 2010) for generous financial support. We also thank the Ministerio de Ciencia e Innovación, Spain (Juan de la Cierva Fellowship to O.B and predoctoral fellowship to I.C.). B.G.D. is a recipient of a Royal Society Wolfson Merit Award and is supported by an EPSRC LSI Platform grant.

Supporting Information Available: Experimental procedures, additional experiments, characterization data and copies of ${ }^{1} \mathrm{H},{ }^{13} \mathrm{C}$ and ${ }^{19} \mathrm{~F}$ NMR spectra for all new compounds. This material is available free of charge via the Internet at http://pubs.acs.org. 